\title{
XLI. Observations on the article "Fermentation," contained in M. Chaptal's nouveau cours complet d' agriculture
}

\section{Duportal M.D.}

To cite this article: M. Duportal M.D. (1811) XLI. Observations on the article "Fermentation," contained in M. Chaptal's nouveau cours complet d' agriculture, Philosophical Magazine Series 1, 38:161, 221-226, DOI: 10.1080/14786441108638632

To link to this article: http://dx.doi.org/10.1080/14786441108638632

曲 Published online: 27 Jul 2009.

Submit your article to this journal $₫$

Џll Article views: 2

Q View related articles $\llbracket$ 
community, will induce the public to prefer a mild disease like vaccination, which where it fails of superseding the small-pox, yet mitigates its violence, and prevents its fatal consequences, to one whose effects are frequently violent; to one which often occasions deformity and blindness; and, when it is contracted by casual infection, has been supposed to destroy one in six in all that it attacks. And it must not be forgotten, that in a public view this constitutes the great objection to inoculation of the small-pox, that by its contagion it disseminates death throughont the empire, whilst vaccination, whaterer be the comparative security which it affords to individuals, occasions no subsequent disorder, and has never, by the most violent of its opposers, been charged with producing an epidemical sickness.

July 18,1811 .

By Order of the Board, Jas. Hervey, Register.

XLT. Observations on the Article "Fermentation," contained in $M$. Chaptas's Nouveau Cours complet d'Agriculture. By M. Dupontal, M. D. Professor of Physic and Chemistry in the Academy of Alontpellier, \&ic. * $T_{n}$ stances is speedily destroyed when their lifegetable subthem. Thesc substances very soon undergo a change in their appearance, the principles which conipose them reacting upon each other; they are arranged in a new order, and in new proportions, whence result products very different from those substances which gave rise to their production.

These products vary according to the nature of the sirbstances, and according to the varions circumstances whoh accompany their change. Thus, vegetable substances which are decomposed in some peculiar circumstances, undergo a spontaneous alseration which is called fermentation, of which the product is bread, an intoxicating liguor, or vinegar, according to the matter subjected to fermentation; while recent herbaceous plants, which putrefy, give rise to the formation of monld.

These are the frets pointed out by $\mathrm{M}$. Chaptal in the work I am now to analyse, Examinum first the fermentation of vegetables of a fieshy and jucy texture, when collected into a large beap, he detaib the conditions, the phaumena, and the result of the process. He afterwards considers the operation in each of the separate parts of

* Anarales de Crimier 1810.

which 
which vegetables consist; he confines himself to the three kinds of fermentation, called the pannary, the vinous, and the acetous. We shall follow the author in his development, and make some observations on the most interesting of his facts.

\section{1st. Of the Pannary Fermentation:}

The making of bread, the food of almost all Europeans, is a domestic chemical operation; since in it those substances which are the most essential to the sustenance of man undergo a change in their nature. These substances are found urited in the meal of the farinaceous seeds, especially in those of wheat, which furnishes the best bread. M. Chaptal has found this latter farina to consist of starch, gluten, mucilage, and sugar. We may add to them the ferment, the vegetable albumen, calcareous phosphate, \&c. which must be reckoned in the number of materials which compose it. What share has each of these principles in carrying on the pannary fermentation ? It is generally believed that the farina being reduced into a paste, the mucous saccharine principle undergoes the vinous fermentation, that the starch has a tendency to become acid, and that the gluten and albumen enter into putrefaction.

I cannot entirely accord with this doctrine. It appears to me to be more correct, to suppose that the ferment, after having converted the sugar of the farina into carbonic acid gas, and into alcohol, changes this into acetic acid; that at the same time the gluten and the albumen are in part decomposed, acetic acid is again produced, some ammonia, and more carbonic acid gas, \&c.; and that, the starch uniting with the undecomposed gluten, there results a compound, the further alteration of wbich is prevented by the action of fire, which combines still nore intimately these principles.

This theory of the pannary fermentation seems to me to be supported by the following facts.

1s1. Those fariux which are deprived of the fermenting principle, or those which scarcely contain any of it, always atford beavy bread, aitbough the muco-sacchaine principle forms a part of them ; for this substance not being a fermentable principle, it cannot ferment of itself, alhough it does so by means of a ferment. Thus, it is customary to add to the dough a leaven, taken from bread already fermented, or the yeast of beer, as is the practice in Paris.

2. Duugh is always acid, notwithstauding that the volatile 
tile alkali formed in the operation neutralizes one part of the acetic acid, as is proven by the ammoniacal odour of dough treated by potass. Bread itself always contains a little of this acid, which heightens the flavomr of it.

3. The starch, the undecompused gluten, and the other materials of the dough, ate so intimately united by the baking, that it is no longer possible to separate them. We can discover by the distillation of bread an animal matter, for it forms ammoniacal acetate; but a less quantity of this is obtained from it than of farina, according to the observations of M. Vauquelin.

4. The formation of carbonic acid gas is rendered evident by the volume which the dongh acquires, and by the numerous cavities which are seen in it. This gas escaping while the bread is baking, dilates the mass still more, which causes the air to lodge in those cavities ; an important circumstance,- - whence results, say they, the remarkable whiteness of bread, full of little holes, so light, delicate and sapid, in comparison with the bread destitute of them, which is heavy, compact, and of a disagreeable taste.

It is therefore more particularly the ferment which has the most active share in producing pannification.. Added to dough in small quantity, the operation is slow and incomplete; in too large proportion, the fermentation goes on so rapidly that it becomes necessary to check it. In this last case M. Chaptal proposes to knead some carbonate of potass with the dough, which will neutralise the excess of acetic acid. Our grood housewives content themselves with uncovering the dough, dividing it, and exposing it to the air, in order to diminish the temperature of the fermenting mass; and this management sometimes succeeds.

\section{Of the Vinous Fermentation.}

This operation can only take place when sugar, water, and a ferment are mixed together. Sugar is the matter of fermentation; the ferment is the agent of it; the presence of water is a necessary condition, as well as a certain degree of temperature. It is hecause these three substances exist in a state of union in the saccharine juices, that these are capable of the vinous fermentation.

What are the chemical changes which substances subjecled to the vinous fermentation undergo? If one considers the composition of these substances, and that of the products of the operation, it will be easy to conctive with M. Thenard, that in it the ferment takes away from the 
sugar a small quantity of nxygen, whereby it becomes a substance sui generis, whose principles not being able to remain in their present arrangement, react upon each other, combine in a new ard different order, producing alcohol dissolved in water, and more carbonic acid gas; the ferment which caused these phanomena is itself altered in part, and precipitated; while the water only serves to bring the molecules into contact, and to retain the alcuhol.

The methods in use for subjecting different substances to the vinous fermentation, may, according to $M$. Chaptal, be reduced to two; decoction and expression. The first is practised by means of water in the fermentation of the farinaceous grains, in making beer ; the second is employed ii fermentation of juices which afford the different sorts of wine. The details furnished by the author on the preparation of beer being borrowed from Thomson, 1 shall not notice them, especially as I have a great number of facts to relate on the art of making wine.

\section{On the vinous Fermentation of the Juice of the Grape.}

The sugar and the ferment existing isolated in the grape, it becomes necessary to press this fruit to obtain from it the juice called must, in which these two vegetable principles are mixed togelber. This must speedily ferments at the temperature of $12^{2}$ of Reaumur*. M. Chaptal says it is necessary to fill the rat all at once, in order to avoid the successive fermentations that take place when the must is put in at various times, as this circumstance renders the wine of a bad quality.

This may be the case indeed in countries to the north, where the grapes being very watery, and but little sweet, cannot support any derangrment in the fermentation; but in these southern climates this phanomenon seldon shows itself. It must necessurily require many days to fill a vat which contains 50 mulds, and yet, however, the wine is very excellent which is made in this enormonsly large vessel.

Before the must is put into the vat, this latter ought to be cleaned with the grieitest care; then the liquor is to be left to terment in it. According to M. Chaptal, the vinous fennenation is influenced by a variety of circunstances, into which I am successively to inquire.

1. Of the Infuence of Temperature on Vinous Fermentation. Twelve degrees of Rcaumur's thermometer appears to be

* About 60 of Falirenheit. 
the most suitable temperature for the vinous fermentation. Below this degree it languishes; above it, it becomes tumultuous. But it is not the temperature of the place only, where the fermentation is going on, which influences it ; the Abbé Rozier has proved that the temperature of the grapes, at the time of the vintage, has a considerable effect upon it, that the fermentation is always slow in proportion to the low temperature of the grapes when they are gathered. This phænomenon was observed last year at Montpellier. The vintage did not commence till the latter end of October, and the weather was cool ; the must fermented badly in the vat, and the wine produced from it was not so strong; it appeared more tart than usual when it was tunned. This wine did not part with its bad qualities until it had undergone a new fermentation in the vessel, which continued some months.

One very singular circumstance, and which has been shown by M. Chaptal, is, the difficulty of restoring the temperature of must, when it is very low, so as to make the fermentation go on in a regular manner. "I diluted," says the author, "some extract of the must of grapes, with water at four degrees above the freezing point. I added some yeast of beer to accelerate the fermentation. The fermentation took place in a short time, when the temperature was elevated to 16 degrees, but it very soon diminished. A tike quantity of extract diluted. and heated to the temperature of 16 degrees, for two days before the yeast was added to it, underwent a very regular and complete fermentation."

\section{On the Influence of Air on the Vinous Fermentation.}

In order that fermentation may take place, and go through its stages in a steady and regular manner, it is necessary that there be a free communication between the fermenting mass and the air. Should we not conclude from this fact, that the air enters as a principle into the product of this operation, or as an element of decomposition? The experiments of $\mathrm{M}$. Chaptal contradict this conclusion, for he has never seen the air absorbed in the vinous fermentation. Its influence is confined to the facilitating the disengagement of the carbonic acid gas produced, the presence of which would check and even stop the fermentation. The free contact of air, although so useful in this respect, has, however, one disadvantage, that it occasions a cunsiderable loss of aroma and alcohol. Thus it is well known that wine fermented in vessels nearly close, is Vol.38. No. 161. Sept. 1811. 
often the most generous and of the most agreeable flavour. It is to secure these advantages, without totally interrupting the communication with the air, that M. Chaptal advises to cover the vat with boards upon which is suspended a covering of old linen cloths; --an excellent method, and easily put in practice, as the cost of it is so trifling.

The loss of alcohol in the vinous fermentation is proved by the experiments of Dom Gentil, and by the happy application of them by $M$. Chaptal, in his manufactory of vinegar. It is also proved, probably, by the two following facts. Some white grapes found whole, by $M$. Coste, at the top of the vat in the time of tunning, tasted precisely like grapes preserved in brandy. I also saw some grapes, under similar circumstances, entirely coated with small crystals of acidulated tartrite of potass. Do not these two phanomena show that the grapes had absorbed a portion of the alcohol which escaped during fermentation, and were thereby deprived of a certain quantity of their water of vegetation? I bave no hesitation in thinking so.

[To be continured.]

XLII. Intelligence and Miscellaneous Articles.

THE COMET.

Olservations of the Appearance of the Comet. By W. Crane, Esq. of Boston, Lincolnshire.

The brilliant appearance which the comet now makes in the north, having excited the attention nut only of the students in astronomy, but also that of the public at large, I hope it will direct many to the pursuit of that beautiful and interesting science; for, in this country, it must be observed with regret that it has not been of late cultivated with the ardour its importance demands.

The following observations on the comet have been taken, at eight o'clock in the evening, according to the dates below :

From the circumstance of my being, at present, in a town where I cannot bave access to astronomical instruments, I am under the netessity of using a quadrant of my own construction : it is made of well dried mabogany, and its radius is $14 \frac{1}{4}$ inches, which gives nearly $3-10$ ths of an inch for a degree. I therefore flatter myself they are not very erroneous. Its situation respecting the right ascension and declination, being taken from Senex's 18-inch celestial globe, 